\title{
BMJ Open Association between cognitive declines and disability in activities of daily living in older adults with COPD: evidence from the China health and retirement longitudinal study
}

\author{
Bingyan Gong, Shaomei Shang, Chao Wu
}

To cite: Gong B, Shang S, Wu C. Association between cognitive declines and disability in activities of daily living in older adults with COPD: evidence from the China health and retirement longitudinal study. BMJ Open 2020;10:e040098. doi:10.1136/ bmjopen-2020-040098

- Prepublication history for this paper is available online. To view these files, please visit the journal online (http://dx.doi. org/10.1136/bmjopen-2020040098).

Received 05 May 2020 Revised 14 September 2020 Accepted 08 October 2020

Check for updates

(c) Author(s) (or their employer(s)) 2020. Re-use permitted under CC BY-NC. No commercial re-use. See rights and permissions. Published by BMJ.

School of Nursing, Peking University, Beijing, China

Correspondence to

Dr Chao Wu;

chelseawu@pku.edu.cn

\section{ABSTRACT}

Objectives This study aimed to investigate the relationship between disability and domain-specific cognitive function in older adults with chronic obstructive pulmonary disease (COPD).

Design Cross-sectional analyses combined with retrospective longitudinal analyses.

Setting We included 450 communities in China. Participants In this study, 1022 (mean age: $68.6 \pm 6.3$; 612 males) and 152 (mean age: 67.0 $55.2 ; 83$ males) older adults with COPD from the China Health and Retirement Longitudinal Study were included in a cross-sectional multivariate linear regression analysis and a longitudinal logistic regression analysis, respectively.

Outcome measures Disability was determined by the difficulty or inability to complete 1 of the 12 activity items in basic activities of daily living (ADL) and instrumental ADL. The cognitive dimensions of episodic memory, attention/numerical ability, orientation to time, and visuospatial ability were assessed via the immediate/ delayed recall task, serial sevens task, naming the current date and pentagon-figure-drawing tasks, respectively.

Results Of 1022 older respondents with COPD at wave- $4,48.5 \%$ had ADL disability. Declines in the global cognitive function $(\beta(95 \% \mathrm{Cl})=-0.627(-1.214$ to $-0.040))$, orientation to time $(\beta(95 \% \mathrm{Cl})=-0.207(-0.364$ to -0.050$))$ and visuospatial ability $(\beta(95 \% \mathrm{Cl})=-0.068$ $(-0.127$ to -0.009$))$ were significantly associated with the presence of ADL disability, when demographic and healthrelated variables were adjusted. Of 152 older participants with COPD and without ADL disability in wave-2, 61 (40.1 $\%$ ) developed disability over a 2-year follow-up. Relative to the participants without a decline in orientation to tine, those with the condition had greater odds of incidence of ADL disability increased by a factor of about 1.46 over a 2-year follow-up.

Conclusions In older adults with COPD, orientation to time and visuospatial inability are vulnerable to the presence of a disability. Prevention of a decline in orientation to time might help prevent disability in older people with COPD.
Strengths and limitations of this study

- A cross-sectional analysis combined with a longitudinal analysis was used to confirm the association between disability and cognitive function in a relatively large population of the older individuals with chronic obstructive pulmonary disease (COPD).

- Extensive variables of sociodemographic, comorbidities and health-related physical and mental status were adjusted in the cross-sectional analysis.

- Both global and domain-specific cognitive functions of older patients with COPD were analysed.

- The follow-up period was only about 2 years.

- Many older individuals (78\%) with COPD were excluded from the longitudinal analysis because of missing information on related observation variables.

\section{INTRODUCTION}

Chronic obstructive pulmonary disease (COPD) is a progressive chronic lung disease characterised by both pulmonary and systemic complications. ${ }^{1-3}$ The exacerbation of COPD is associated with disability and premature mortality in ageing people. ${ }^{45}$ The Global Burden of Diseases study estimates that COPD ranks within the top 10 diseases that cause disability globally, as measured by disability-adjusted life years in 2017 and caused about 3.2 million deaths worldwide. ${ }^{67}$ Between 2012 and 2015, the overall prevalence of spirometry-defined COPD was about $8.6 \%$ in China, and the prevalence was higher in older people. ${ }^{8}$ Besides the multiple somatic comorbidities of COPD, including cardiovascular disease, lung cancer, metabolic syndrome and diabetes, arthritis, frailty and anaemia, ${ }^{9} 10$ mental comorbidities including depression, sleep disturbances and cognitive decline have become the target of intervention for these conditions, leading to 
a dramatic decline in the quality of life in patients with COPD. ${ }^{11-15}$

Cognitive impairment has been recognised in most (60\%-80\% of the population) patients with COPD. ${ }^{11}{ }^{15-18}$ Previous studies have found that working memory, cognitive processing speed, psychomotor function and language abilities are affected in patients with COPD. ${ }^{11} 161819$ Cognitive dysfunction may be partially accounted for by airflow limitation, hypoxia, inflammation or cerebral microbleeds. ${ }^{12}{ }^{18} 19$ However, some studies have revealed that the severity of cognitive impairment in patients with COPD is not related to the severity of hypoxemia and lung function, ${ }^{16}$ suggesting that there might be other factors that account for cognitive deficits in patients with COPD. Previous studies on health promotion have found that in older adults, spending much time sitting or maintaining immobility is associated with increased odds of cognitive impairment, independent of the amount of physical activity. ${ }^{20}{ }^{21}$ Therefore, reduced activities of daily living (ADL) or disability in patients with COPD may, in turn, exacerbate cognitive impairment.

Besides cognitive impairment, various non-respiratory factors, including comorbidities, abnormal body composition, frailty and depression, have been found to contribute to disability in COPD. ${ }^{22-25}$ Although several cross-sectional studies have explored the association between cognitive impairment and disability in patients with COPD, ${ }^{2324} 2627$ the respiratory and non-respiratory covariates still need to be adequately controlled. Moreover, the cognitive dimension related to disability in older patients with COPD remains unclear. Answering this question may be of clinical significance in the intervention of COPD disability.

In this study, we examined the cross-sectional and longitudinal association of disability ${ }^{23}$ (evaluated by the terms of basic ADL (BADL) and instrumental ADL (IADL)) with the global cognitive function and four cognitive dimensions in older adults with COPD (including chronic bronchitis, emphysema and pulmonary heart disease), using a national representative sample from the China Health and Retirement Longitudinal Study (CHARLS).

\section{METHODS}

\section{Participants}

The data used in this study were derived from the CHARLS, a nationally representative cohort study of a longitudinal survey conducted by the National School for Development (China Center for Economic Research) at Peking University. The survey began in 2011, and was followed up every 2 years, to serve the needs of scientific research on people aged above 45 years in China. The sample included 28 provinces, 150 county-level units and 450 communities. CHARLS data are publicly accessible and more details about CHARLS can be found on the official website: http://charls.pku.edu.cn/en. The CHARLS was conducted following the Code of Ethics of the World Medical Association (Declaration of Helsinki) for experiments involving humans.

All participants accepted a face-to-face household interview in which a structured questionnaire was used. In this study, a diagnosis of COPD was confirmed through two questions. Participants were first asked whether a doctor diagnosed them with COPD. If they responded affirmatively, they were then asked how they became aware of the diagnosis (by a routine physical examination, a physical examination organised by their work unit or community, a physical examination organised by the CHARLS or by other means). A subject was defined as having COPD if he or she responded 'yes' to the first question and had a complete answer to the second question.

We used the 2015 (wave-4) CHARLS data involving 21095 respondents to conduct a cross-sectional analysis. The following individuals were excluded from the analysis: (1) individuals without COPD ( $\mathrm{n}=18231)$, (2) participants aged below 60 years $(\mathrm{n}=938)$, (3) individuals suffering from psychiatric problems $(n=84)$, selfreported memory-related diseases $(n=112)$, brain damage or mental retardation $(\mathrm{n}=103)$ and (4) participants with missing other covariates $(n=605)$. Finally, the remaining 1022 individuals were included in our cross-sectional analysis (figure 1A). We used the wave-2 (2013; involving 18612 respondents) and wave-4 (2015) CHARLS data to conduct a longitudinal analysis. The following subjects were excluded from the analysis: (1) individuals who did not attend the wave-4 interview $(\mathrm{n}=5878)$; (2) participants who did not report whether they were diagnosed as COPD $(\mathrm{n}=474)$ and participants without COPD at wave-2 ( $\mathrm{n}=10851)$; (3) participants with missing ADL data $(\mathrm{n}=171)$ and who either had a BADL disability $(\mathrm{n}=299)$ or IADL disability $(\mathrm{n}=204)$ in wave-2, and participants with missing information of cognitive function $(n=46)$; (4) participants aged below 60 years in wave-2 and those with unmatched age in wave-4 $(\mathrm{n}=340)$; (5) individuals who reported a history of stroke or self-reported mental disorder $(\mathrm{n}=24)$; and (6) participants who had other covariates missing $(n=173)$. Finally, the remaining 152 individuals were included in our longitudinal analysis (figure 1B).

\section{Measurements \\ Cognitive function}

In CHARLS, cognitive function was assessed using tools included in an adapted Chinese version of the Mini-Mental State Examination. ${ }^{28}$ The assessment of cognitive function involved measurement of four dimensions including episodic memory (immediate recall and delayed recall), attention/numerical ability, orientation to time and visuospatial ability. ${ }^{29}{ }^{30}$ For assessing episodic memory, participants were asked to memorise and repeat as many words as they could immediately (immediate recall) and a few minutes later (delayed recall) after an interviewer read out 10 Chinese nouns in random order. ${ }^{31}$ The scores of the immediate recall task and delayed recall task were added up to obtain the score of episodic memory 

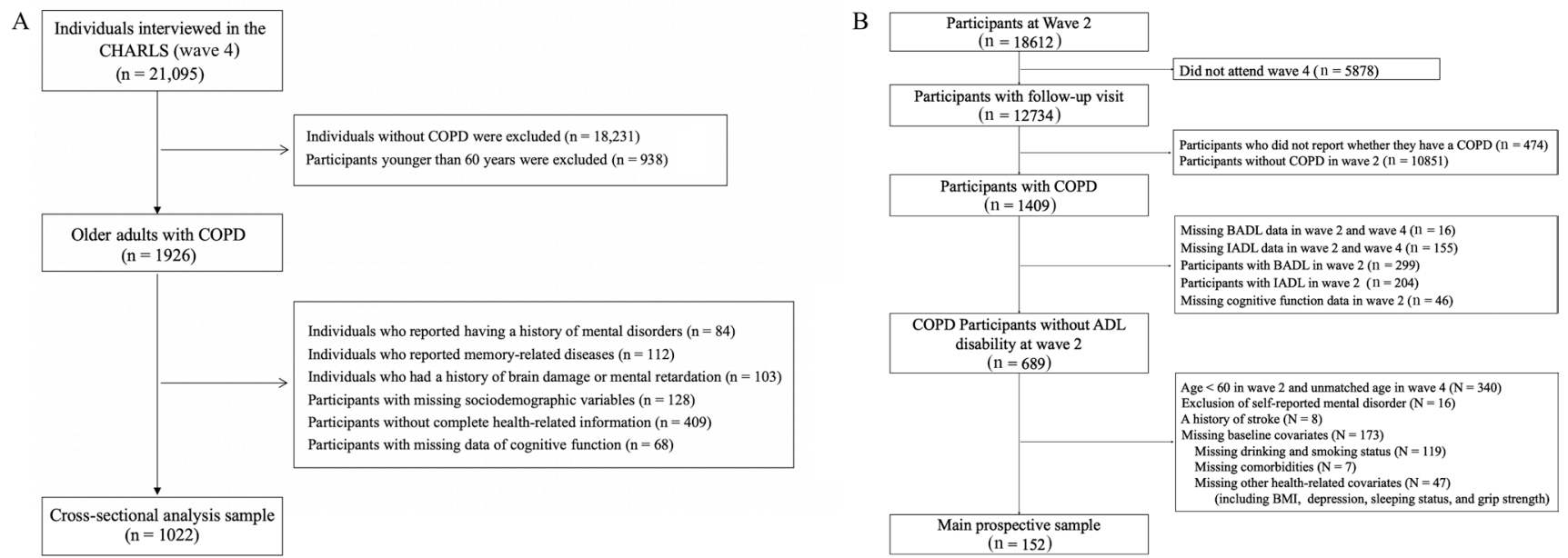

Figure 1 Flow chart of subjects into the analytical sample. (A) The flow of participants into the cross-sectional analytical samples. (B) Flow of participants into the longitudinal analytical samples. Data were from the CHARLS (http://charls.pku.edu. cn/en). ADL, activities of daily living; BADL, basic ADL; CHARLS, China health and retirement longitudinal study; COPD, chronic obstructive pulmonary disease; IADL, instrumental ADL.

(ranging from 0 to 20). ${ }^{32}$ The attention/numerical ability was measured by the serial sevens task: respondents were asked to answer each time 7 was subtracted from 100 (up to five times), and the score was the aggregate number of correct answers. ${ }^{33}$ Orientation to time was measured by asking the participants to name the current date (month, day, year), day of the week and season of the year; the score was the sum number of correct answers and ranged from 0 to $5 .^{34}$ The visuospatial ability was assessed by a figure-drawing task: participants were asked to reproduce a picture of two overlapped pentagons shown by the interviewer; participants who successfully completed the task received a score of $1 .{ }^{30}$ The score of the global cognitive function was the aggregate score of the four cognitive task scores (episodic memory, attention/numerical ability, orientation to time and visuospatial ability) and ranged from 0 to $31 .^{35} \mathrm{~A}$ higher total score or subdimension score indicates superior global or domain-specific cognitive function.

\section{Activities of daily living (ADL)}

Disability in ADL was measured according to BADL and IADL. ${ }^{36}$ BADL disability was defined as difficulty in dressing, bathing, eating, getting into or out of bed, using the toilet and continence control. IADL disability was described as difficulty associated with cleaning, cooking, shopping, financial management, taking medications and making phone calls. Participants were asked whether they had difficulty with each task in the four responses as follows: (1) No, I do not have any difficulty; (2) I have difficulty but I can still do it; (3) Yes, I have difficulty and need help; and (4) I cannot do it. Participants were categorised as having a lack of ability to perform ADL (ADL disability) if they reported difficulty or inability to complete 1 of the 12 activity items.

\section{Covariates}

Covariates included sociodemographic and healthrelated variables. The sociodemographic variables included age, sex, education level, marital status, region of residence, retirement status and number of children. Age was considered a continuous variable. Education level was categorised into four subgroups: illiterate, elementary school, middle school and high school or above. Marital status was defined as married or unmarried (including people who were widowed, divorced or never got married). The region of residence was dichotomised into rural and urban area. Retirement status was categorised into 'Yes' and 'No'. The number of children was categorised into four subgroups: zero, one, two and three or more. Smoking status and alcohol consumption were categorised into 'Yes' or 'No'. 'Yes' meant that they were smoking or drinking alcohol at the time of the study or until last year. We assessed the number of comorbidities from the answer list (yes or no) in the CHARLS data, including hypertension, dyslipidaemia, diabetes, cancer, liver disease, heart problems, stroke, kidney disease, digestive disease, arthritis or rheumatism and asthma. We divided the participants into four groups according to the number of comorbidities: one, two, three and four or more. Self-reported health was categorised into good (very good or good), fair and poor (poor or very poor). Depressive symptoms were measured using the 10-item Center for Epidemiologic Studies Depression Scale (CESD-10, Chinese version). ${ }^{37}$ Other objective measurements including body mass index (BMI, $\left.\mathrm{kg} / \mathrm{m}^{2}\right)$, sleeping hours at night, systolic pressure, diastolic pressure, pulse, peak expiratory flow (PEF) and grip strength (GS) were also collected. PEF (L/min) was estimated using a peak flow metre (Shanghai, China). The GS (in kilogram) of left and right hands was measured three times using a dynamometer (WL-1000, Nantong, China). The best of the three measurements of left and right hands were averaged and used in the statistical analyses.

\section{Statistical analyses}

Statistical analyses were performed using SPSS V.24.0 and $\mathrm{R}$ software V.3.6.3. For comparisons between participants 
with and without ADL disability, Student's t-tests were used for continuous variables, and $\chi^{2}$ tests were used for categorical variables. In cross-sectional analyses, multivariate linear regression analyses were conducted to assess the cross-sectional associations between ADL disability and cognitive function, including global cognitive function and four cognitive dimensions (episodic memory, attention/numerical ability, orientation to time and visuospatial ability). The regression coefficient $(\beta)$ and $95 \%$ CI were then computed for each model. Model 1 was not adjusted for any covariate. In Model 2, sociodemographic variables were adjusted. In Model 3, sociodemographic and certain health-related covariates were adjusted. In longitudinal analyses, because the baseline (wave-1; 2011) data of CHARLS did not measure IADL, we used wave-2 and wave- 4 data. Logistic regression models were fit to estimate the ORs and 95\% CI between wave-2 cognitive function and wave-4 ADL disability.

\section{Patient and public involvement statement}

No patients were involved in setting the research question or the outcome measures, nor were they involved in developing plans for design or implementation of the study. No patient was asked for advice on interpretation or writing of results. There were no plans to disseminate the results of the research to study participants or the relevant patient community.

\section{RESULTS}

The characteristics of the older participants with COPD in wave- 4 are shown in table 1 . A total of 1022 participants (612 males, 410 females) with a mean age of $68.57 \pm 6.26$ years $(68.21 \pm 6.06$ years in the group without ADL disability and $68.96 \pm 6.45$ years in the group with ADL disability) were eligible for data analysis. Fortynine per cent of 1022 participants had an ADL disability. Compared with the participants with COPD and without ADL disability, those with the condition were more likely to be female, less educated, live in the rural areas, have more children, no habit of smoking and more comorbidities, report poor health status, sleep for fewer hours at night and have more severe depressive symptoms, lower PEF and GS, and lower global cognition score and poorer domain-specific cognitive function, including episodic memory $(\mathrm{t}=5.336, \mathrm{p}<0.001)$, attention/numerical ability $(\mathrm{t}=4.923, \mathrm{p}<0.001)$, orientation to time $(\mathrm{t}=7.196, \mathrm{p}<0.001)$ and visuospatial ability $(\mathrm{t}=6.162, \mathrm{p}<0.001$, table 1$)$.

Among the 1022 participants, multivariate linear regression analysis between cognitive measures and ADL disability revealed that ADL disability was cross-sectionally associated with lower scores of the four cognitive dimensions (figure 2A). After controlling for sociodemographic variables in Model 2, we found that episodic memory $(\beta$ $(95 \% \mathrm{CI})=-0.627 \quad(-1.023$ to -0.230$), \mathrm{p}=0.002)$, orientation to time $(\beta(95 \% \mathrm{CI})=-0.330 \quad(-0.477$ to -0.183$)$, $\mathrm{p}<0.001)$, visuospatial ability $(\beta \quad(95 \% \mathrm{CI})=-0.090$ $(-0.145$ to -0.035$), \mathrm{p}=0.001)$ and global cognition $(\beta$
$(95 \% \mathrm{CI})=-1.241 \quad(-1.800$ to -0.682$), \quad \mathrm{p}<0.001)$ were still significantly associated with ADL disability. Further adjustment for health-related factors in Model 3 did not affect the significance of the associations of ADL disability with the global cognitive function $(\beta(95 \% \mathrm{CI})=-0.627$ $(-1.214$ to -0.040$), \mathrm{p}=0.036)$, orientation to time $(\beta$ $(95 \% \mathrm{CI})=-0.207 \quad(-0.364$ to -0.050$) ; \mathrm{p}=0.010$ and false discovery rate (FDR) corrected $\mathrm{p}=0.040$ ) and visuospatial ability $(\beta(95 \% \mathrm{CI})=-0.068 \quad(-0.127$ to -0.009$)$; $\mathrm{p}=0.023$ and FDR corrected $\mathrm{p}=0.046$ ), but the association of ADL disability with episodic memory and attention/ numerical ability were further attenuated and became non-significant $(\beta \quad(95 \% \mathrm{CI})=-0.291 \quad(-0.712$ to 0.129$)$; $\beta(95 \% \mathrm{CI})=-0.061(-0.295$ to 0.173$))$. In Model 3 , the health-related factors associated with better global cognitive function included a younger age, being female, a higher education level, a lower depression level and better lung function. Moreover, being more educated was associated with better function of orientation to time and visuospatial ability (table 2 ). Note that the global cognitive function, as well as the orientation to time and visuospatial ability, was associated with ADL disability, and the association was independent of all the demographic and health-related variables.

Among 152 wave-2 older participants with COPD and without ADL disability, $61(40.1 \%)$ reported difficulty in completing at least one item of the 12 ADLs at the wave- 4 follow-up. Of the 152 older participants with COPD, 127 were also included in the above cross-sectional analysis. Compared with the respondents without ADL disability at wave-4, those with the condition were less educated, had weaker GS, lower global cognitive function score, declined episodic memory and declined orientation to time at the wave-2 interview (table 3). To test whether and which cognitive dimensions contributed to the development of ADL disability over time, longitudinal logistic regression analysis between the wave-2 cognitive function and the incidence of ADL disability in wave- 4 was conducted. The results showed that a decline global cognitive function $(\mathrm{OR}=1.10,95 \% \mathrm{CI}=1.03$ to 1.18$)$, episodic memory $(\mathrm{OR}=1.13,95 \% \mathrm{CI}=1.02$ to 1.26$)$, orientation to time $(\mathrm{OR}=1.53,95 \% \mathrm{CI}=1.14$ to 2.06$)$, but not attention/ numerical and visuospatial ability, were positively associated with odds of ADL disability (figure 2B). Because the educational level and GS differed between the older participants with COPD and with ADL and those without ADL (table 3), in Model 2, education was adjusted and the associations of ADL disability with the decline global cognitive function and orientation to time remained significant (global cognition: $\mathrm{OR}=1.10,95 \% \mathrm{CI}=1.01$ to 1.19; orientation to time: $\mathrm{OR}=1.48,95 \% \mathrm{CI}=1.09$ to 2.02 ). In Model 3, only the association of ADL disability with a declined orientation to time remained significant when GS was further adjusted (OR=1.46, 95\% CI=1.06 to 2.01). Thus, relative to the older participants with COPD without the declined orientation to time, those with the condition had the odds of incidence of ADL disability increased by a factor of about 1.46 . 
Table 1 Participants' characteristics according to ADL disability in wave-4: CHARLS

\begin{tabular}{|c|c|c|c|c|c|}
\hline \multirow[t]{2}{*}{ Characteristic* } & \multirow{2}{*}{$\begin{array}{l}\text { Total } \\
(n=1022)\end{array}$} & \multirow{2}{*}{$\begin{array}{l}\text { Without ADL disability } \\
(n=526)\end{array}$} & \multirow{2}{*}{$\begin{array}{l}\text { With ADL disability } \\
(n=496)\end{array}$} & \multicolumn{2}{|l|}{ Statistics } \\
\hline & & & & $t / \chi^{2}$ & $P$ value \\
\hline \multicolumn{6}{|l|}{ Sociodemographic variables } \\
\hline Male, n (\%) & $612(59.9)$ & $349(66.3)$ & $263(53.0)$ & 18.869 & $<0.001$ \\
\hline Education level, n (\%) & & & & 40.532 & $<0.001$ \\
\hline Elementary school & $534(52.3)$ & $291(55.3)$ & $243(49.0)$ & & \\
\hline Middle school & $125(12.2)$ & $78(14.8)$ & $47(9.5)$ & & \\
\hline High school and above & $64(6.3)$ & $45(8.6)$ & $19(3.8)$ & & \\
\hline Married, n (\%) & $822(80.4)$ & $432(82.1)$ & $390(78.6)$ & 1.987 & 0.159 \\
\hline \multicolumn{6}{|l|}{ Region of residence, $\mathrm{n}(\%)$} \\
\hline Number of children, $\mathrm{n}(\%)$ & & & & 9.195 & 0.027 \\
\hline Having no children & $13(1.3)$ & $6(1.1)$ & $7(1.4)$ & & \\
\hline Having one child & $56(5.5)$ & $38(7.2)$ & $18(3.6)$ & & \\
\hline Having two children & $243(23.8)$ & $134(25.5)$ & $109(22.0)$ & & \\
\hline Three children or more & $710(69.5)$ & $348(66.2)$ & $362(73.0)$ & & \\
\hline \multicolumn{6}{|l|}{ Health-related variables } \\
\hline Drinking (yes), n (\%) & $532(52.1)$ & $285(54.3)$ & $247(49.8)$ & 2.058 & 0.151 \\
\hline Smoking (yes), n (\%) & $618(60.5)$ & $343(65.2)$ & $275(55.4)$ & 10.185 & 0.001 \\
\hline Good & $131(12.8)$ & $87(16.5)$ & $44(8.9)$ & & \\
\hline Fair & $539(52.7)$ & $321(61.0)$ & $218(44.0)$ & & \\
\hline Poor & $352(34.4)$ & $118(22.4)$ & $234(47.2)$ & & \\
\hline BMI $\left(\mathrm{kg} / \mathrm{m}^{2}\right)$, mean (SD) & $23.9(5.1)$ & $23.0(5.3)$ & $23.0(4.8)$ & 0.033 & 0.97 \\
\hline $\begin{array}{l}\text { Sleep hour at night, } \\
\text { mean (SD) }\end{array}$ & $6.1(2.1)$ & $6.4(1.9)$ & $5.8(2.2)$ & 4.386 & $<0.001$ \\
\hline CESD-10 score, mean (SD) & $9.5(6.6)$ & $7.5(5.6)$ & $11.7(7.0)$ & -10.709 & $<0.001$ \\
\hline Systolic pressure (mmHg), mean (SD) & $130.7(21.0)$ & $130.4(20.1)$ & $130.9(219)$ & -0.411 & 0.681 \\
\hline Diastolic pressure (mmHg), mean (SD) & $74.4(12.3)$ & $74.2(12.1)$ & $74.7(12.5)$ & -0.566 & 0.572 \\
\hline Pulse (bpm), mean (SD) & $75.5(11.9)$ & $75.1(11.1)$ & $75.9(12.7)$ & -1.055 & 0.292 \\
\hline PEF (L/min), mean (SD) & $210.9(110.8)$ & $223.5(113.9)$ & $197.4(105.8)$ & 3.79 & $<0.001$ \\
\hline GS $(\mathrm{kg})$, mean (SD) & $28.8(9.0)$ & $30.9(8.7)$ & $26.60(8.9)$ & 7.761 & $<0.001$ \\
\hline \multicolumn{6}{|l|}{ Cognitive function } \\
\hline Global cognition, mean (SD) & $11.5(5.5)$ & $12.7(5.4)$ & $10.2(5.4)$ & 7.578 & $<0.001$ \\
\hline Episodic memory, mean (SD) & $5.6(3.5)$ & $6.2(3.5)$ & $5.0(3.4)$ & 5.336 & $<0.001$ \\
\hline $\begin{array}{l}\text { Attention/numerical ability, } \\
\text { mean (SD) }\end{array}$ & $2.7(2.0)$ & $3.0(1.9)$ & $2.4(2.0)$ & 4.923 & $<0.001$ \\
\hline
\end{tabular}

Continued 
Table 1 Continued

\begin{tabular}{|c|c|c|c|c|c|}
\hline Characteristic* & Total & Without ADL disability & With ADL disability & Statistic & \\
\hline & $(n=1022)$ & $(n=526)$ & $(n=496)$ & $t / \chi^{2}$ & $P$ value \\
\hline Orientation to time, mean (SD) & $2.6(1.4)$ & $2.9(1.3)$ & $2.3(1.4)$ & 7.196 & $<0.001$ \\
\hline
\end{tabular}

*Values are mean (SD) or $\mathrm{n}(\%)$ as appropriate.

ADL, activities of daily living; BMI, body mass index; CESD-10, 10-item center for epidemiologic studies depression scale; CHARLS, China health and retirement longitudinal study; GS, grip strength; PEF, peak expiratory flow.

Note that when other demographic variables (age, sex and marital status), drinking and smoking status, comorbidities, depressive symptoms and sleep status were further adjusted, the association remained significant. However, when either the PEF or the region of residence (although the differences in the two variables between groups were not significant) was included in the model, the association became insignificant, suggesting that lung

A

Model 1

\section{$\beta$}

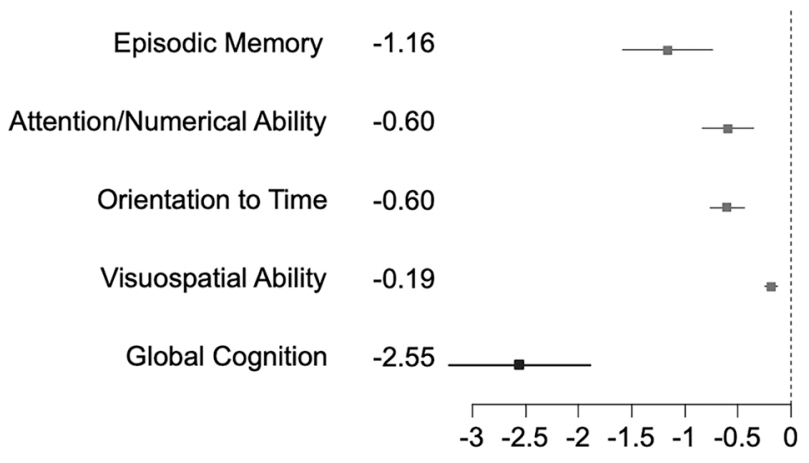

B

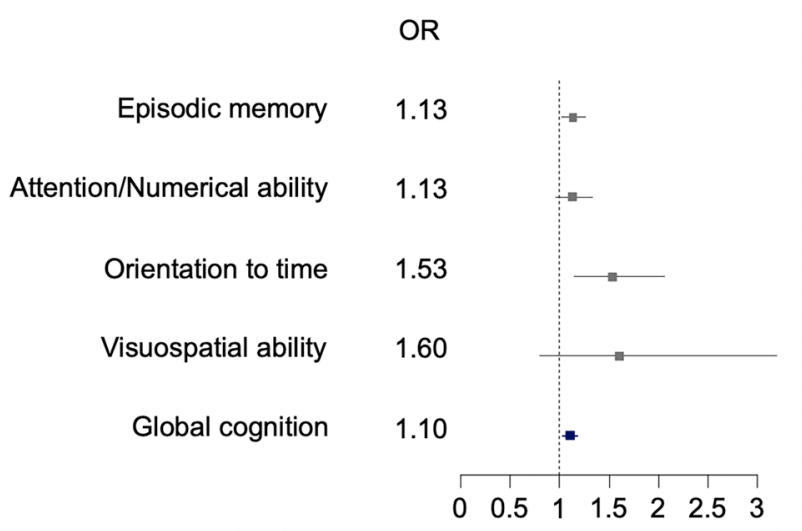

function, economic status and medical resources may affect the relationship between cognitive impairment and disability in older people with COPD.

\section{DISCUSSION}

Cross-sectional analyses showed that older Chinese adults with COPD and with disabilities had worse performance

Figure 2 Forest plots of the association between cognitive decline and ADL disability. (A) Cross-sectional analysis: Model 1 is the unadjusted model. Model 2 adjusted for sociodemographic factors: age, sex, education level, marital status, region of residence, retirement status and number of children; Model 3 further adjusted for the health-related factors: drinking and smoking status, comorbidity, self-reported health, BMI, sleep duration at night, depressive symptoms, systolic pressure, diastolic pressure, pulse, PEF and GS. (B) Longitudinal analysis: Model 1 is the unadjusted model. Model 2 adjusted for education level. Model 3 further adjusted for GS. ADL, activities of daily living; BMI, body mass index; COPD, chronic obstructive pulmonary disease; GS, grip strength; PEF, peak expiratory flow. 


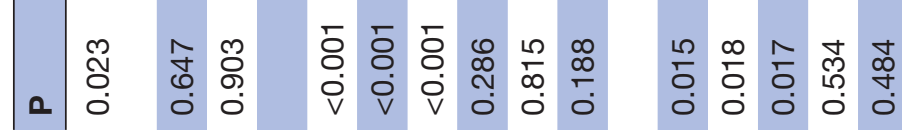

를

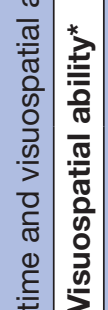

웅

돌

한

음

范

$\sum_{1}^{\infty}$

응

$\stackrel{0}{ \pm}$

은

플

通

궁

\section{这}

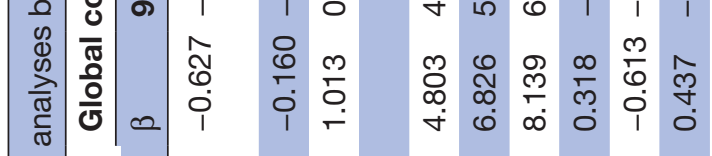

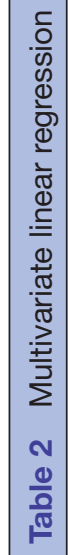

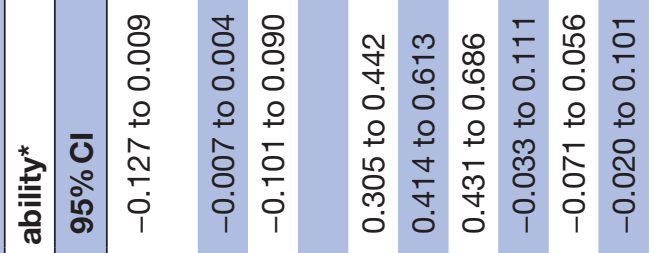

$\overline{\frac{\pi}{7}}$ $>\infty$

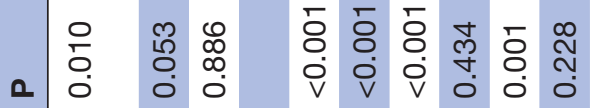

융 유 유

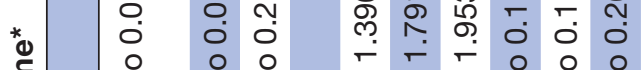

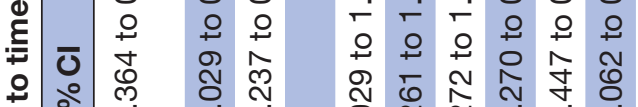

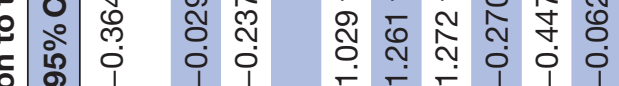

의 1

๑)

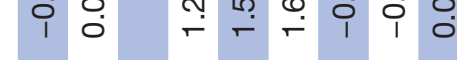

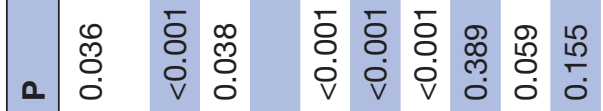

융 \&

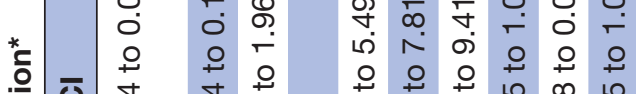

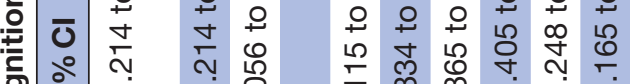

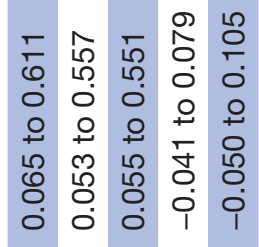

œ लై

న్

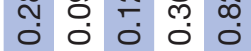

ભํ. $\leftarrow+\frac{0}{-}$ 오오 우우

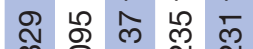
m. i 1 i 1 i

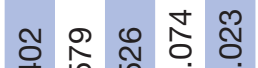

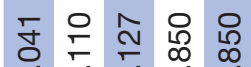
品

8 मे 엉ㅇㅇㅇ 는 F - $\begin{gathered}0 \\ 0\end{gathered}$

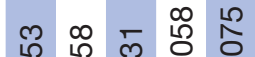

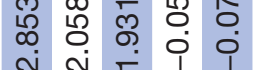

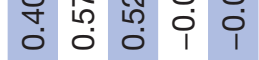

$\begin{array}{lll}0 & 0 \\ 0 & 0 & 0 \\ 0 & 0 & 0 \\ 0 & 0 & 0 \\ 0 & 0 & 0\end{array}$

チ 둥

우 우 우

$\infty$ 음읻

i

กิ ชิ

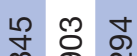
范

लి त्रे

० 0 0

오 우

co

o o

ตัด ำ ำ

O.

$\leftarrow \infty$

雚衣 $\frac{m}{m}$

०० 0 .

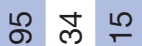

गे

아 오 우

$\infty$ 음

त क ह

i i i

$\infty \wedge$

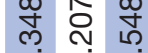

वे 0
๕ o 00 o

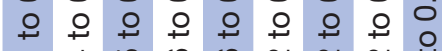
두 항 늉 i $\begin{aligned} & \text { i } \\ & 1\end{aligned}$

용

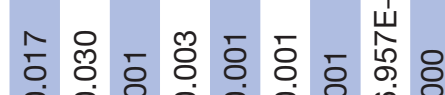
i

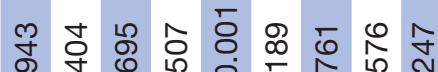
O 0 O

மூ กั0

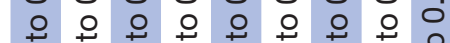

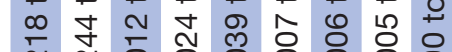
กิ $\begin{array}{lllllllll}1 & 1 & 1 & 1 & 1 & 1 & 1 & 1 & 0\end{array}$ ஜํำ $\begin{array}{llllllll}0 & 1 & 0 & 0 & 1 & 1 & 0 & 0 \\ 0\end{array}$

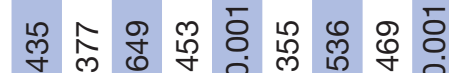

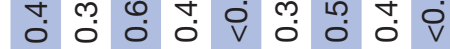

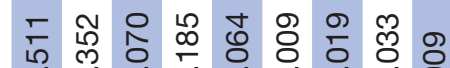

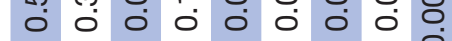
웅ㅇㅇㅇㅇㅇㅇㅇㅇㅇㅇㅇㅇ 穴

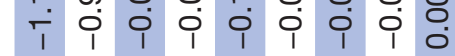

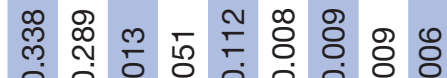

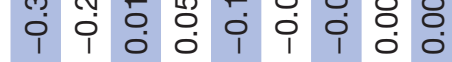

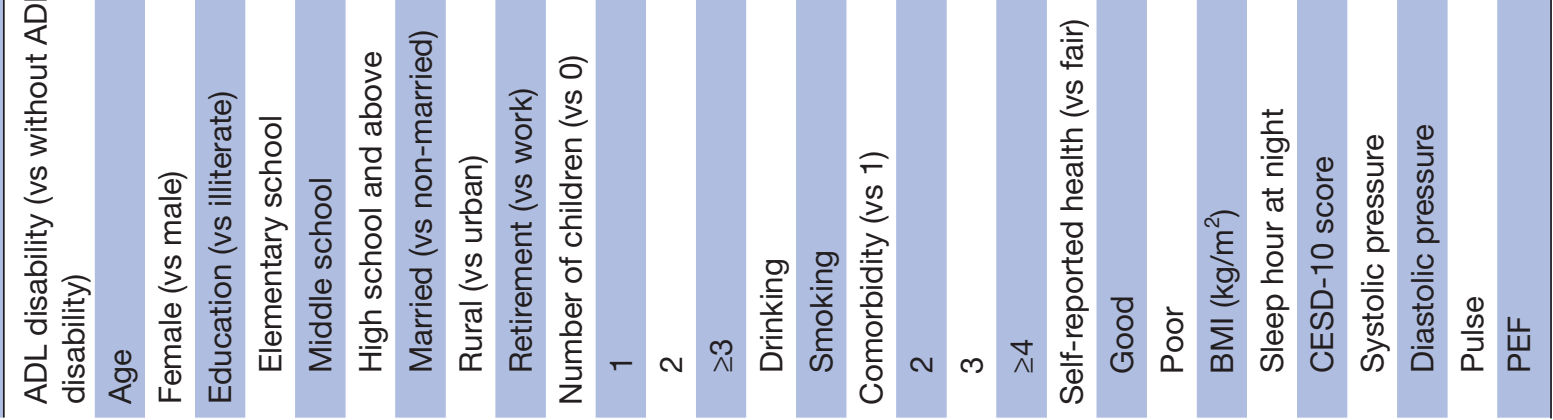


in global cognitive function and four cognitive dimensions, including episodic memory (immediate recall and delayed recall), attention/numerical ability, orientation to time and visuospatial ability than those without a disability. Moreover, the orientation to time and visuospatial ability were associated with ADL disability independent of demographic variables and other health-related factors, including drinking and smoking status, comorbidities, sleeping status, BMI, depressive symptom, GS and PEF. Longitudinal analyses further confirmed that declined orientation to time increased the incidence of ADL disability by odds of about 1.46 over a 2-year follow-up in older adults with COPD.

In this study, the prevalence of disability was $48.53 \%$ in older people with COPD, which is inconsistent with a previous study reporting that the prevalence of disability is globally $12.8 \%$ among Americans with COPD. ${ }^{27}$ This discrepancy may be accounted for by the fact that people aged 53 and above were included in their study. The Rodríguez-Rodríguez $e t a l^{88}$ study reported $21.8 \%$ and $31.9 \%$ ADL disability in $60-79$ years old male and female individuals, respectively. They also reported an IADL disability prevalence of $37.5 \%$ in men and $41.5 \%$ in women, ${ }^{38}$ which is consistent with the disability prevalence in this study. Another study using the Valued Life Activities Scale reported that $26 \%$ of people with COPD would develop disability, ${ }^{24}$ indicating that the prevalence of disability varies when different disability measurements or standards are adopted.

The results of this study showed that compared with participants with COPD and without disability, those with the condition were less educated, more likely to live in rural areas, have more comorbidities, more severe depressive symptoms and a weaker GS, which is in line with the results of previous studies reporting that people with disabilities are vulnerable to chronic health concerns. ${ }^{39-43}$ Besides extrapulmonary factors, we also found a lower PEF in the participants with COPD with a disability. This is consistent with previous studies showing that lung function would be worsened by the presence of disability in persons with COPD. ${ }^{38}$ Because tremendous studies have shown that chronic comorbidities, frailty, depression and unhealthy lifestyles and behaviours affect cognitive function, ${ }^{44-48}$ in our study, the covariates were adequately adjusted during the cross-sectional regression analysis of ADL disability with cognitive domains in older people with COPD.

Previous studies have found an association between disability and global cognitive dysfunction in patients with COPD. ${ }^{23} 242627$ Our results extend these previous findings by revealing that the cognitive dimensions of orientation to time and visuospatial ability, but not episodic memory and attention/numerical ability, were affected by disability in patients with COPD, suggesting that the ability to process time and mental space might be most vulnerable to disability in COPD. Several studies have found that the weakening of time and space awareness may be an early sign of cognitive decline or dementia. ${ }^{49-51}$ 
Table 3 Wave-2 (2013) characteristics according to ADL disability in wave-4 (2015) in older individuals with COPD: CHARLS

\begin{tabular}{|c|c|c|c|c|c|}
\hline Characteristic $^{*}$ & Overall & No disability & Disability & $t / \chi^{2}$ & $\mathrm{Pt}$ \\
\hline & $(n=152)$ & $(n=91)$ & $(n=61)$ & & \\
\hline Age, mean years (SD) & $67.0(5.2)$ & $66.5(5.2)$ & $67.7(5.2)$ & 1.383 & 0.169 \\
\hline Female, n (\%) & $69(45.4)$ & $37(40.7)$ & $32(52.5)$ & 1.603 & 0.206 \\
\hline Education, n (\%) & & & & 3.843 & 0.050 \\
\hline Illiterate & $35(23)$ & $16(17.6)$ & $19(31.1)$ & & \\
\hline Elementary & $37(24.3)$ & $23(25.3)$ & $14(23)$ & & \\
\hline Middle school & $43(28.3)$ & $25(27.5)$ & $18(29.5)$ & & \\
\hline High/vocational school & $32(21.1)$ & $25(27.5)$ & $7(11.5)$ & & \\
\hline College and above & $5(3.3)$ & $2(2.2)$ & $3(4.9)$ & & \\
\hline Living with partner, n (\%) & $129(84.9)$ & $81(89)$ & $48(78.7)$ & 2.280 & 0.131 \\
\hline Living in rural area, $\mathrm{n}(\%)$ & $93(61.2)$ & $50(54.9)$ & $43(70.5)$ & 3.091 & 0.078 \\
\hline Retired (\%) & $56(36.8)$ & $37(40.7)$ & $19(31.1)$ & 1.041 & 0.308 \\
\hline Number of children, mean (SD) & $4(1)$ & $4(1)$ & $4(1)$ & -0.123 & 0.903 \\
\hline Drinking frequency, n (\%) & & & & 1.734 & 0.188 \\
\hline No drinker & $118(77.6)$ & $67(73.6)$ & $51(83.6)$ & & \\
\hline Once a month & $2(1.3)$ & $2(2.2)$ & $0(0)$ & & \\
\hline 2-3 times a month & $5(3.3)$ & $4(4.4)$ & $1(1.6)$ & & \\
\hline Once a week & $5(3.3)$ & $4(4.4)$ & $1(1.6)$ & & \\
\hline $2-3$ times a week & $5(3.3)$ & $4(4.4)$ & $1(1.6)$ & & \\
\hline 4-6 times a week & $1(0.7)$ & $0(0)$ & $1(1.6)$ & & \\
\hline Once a day & $7(4.6)$ & $3(3.3)$ & $4(6.6)$ & & \\
\hline Twice a day & $5(3.3)$ & $4(4.4)$ & $1(1.6)$ & & \\
\hline More than twice a day & $4(2.6)$ & $3(3.3)$ & $1(1.6)$ & & \\
\hline Smoking status, n (\%) & & & & 0.874 & 0.350 \\
\hline No smoker & $122(80.3)$ & $68(74.7)$ & $54(88.5)$ & & \\
\hline 1-10/day & $10(6.6)$ & $8(8.8)$ & $2(3.3)$ & & \\
\hline 11-20/day & $8(5.3)$ & $5(5.5)$ & $3(4.9)$ & & \\
\hline 20-40/day & $11(7.2)$ & $9(9.9)$ & $2(3.3)$ & & \\
\hline$>40 /$ day & $1(0.7)$ & $1(1.1)$ & $0(0)$ & & \\
\hline \multicolumn{6}{|l|}{ Comorbidity, n (\%) } \\
\hline Hypertension & $53(34.9)$ & $27(29.7)$ & $26(42.6)$ & 2.158 & 0.142 \\
\hline Diabetes & $12(7.9)$ & $8(8.8)$ & $4(6.6)$ & 0.249 & 0.618 \\
\hline Heart disease & $36(23.7)$ & $18(19.8)$ & $18(29.5)$ & 1.412 & 0.235 \\
\hline BMI $\left(\mathrm{kg} / \mathrm{m}^{2}\right)$, mean (SD) & $23.2(4.0)$ & $23.7(4.1)$ & $22.5(3.7)$ & -1.879 & 0.062 \\
\hline GS (kg), mean (SD) & $28.5(9.1)$ & $30.3(9.0)$ & $25.9(8.7)$ & -2.989 & 0.003 \\
\hline $\begin{array}{l}\text { Night sleep duration (hours), } \\
\text { mean (SD) }\end{array}$ & $6.2(1.9)$ & $6.1(1.9)$ & $6.3(2.0)$ & 0.592 & 0.556 \\
\hline $\begin{array}{l}\text { Depressive symptoms (CESD-10), } \\
\text { mean (SD) }\end{array}$ & $7.9(5.2)$ & $7.6(5.2)$ & $8.3(5.2)$ & 0.729 & 0.467 \\
\hline PEF (L/min), mean (SD) & $200.0(113.9)$ & 208.7 (112.2) & $186.9(116.2)$ & -1.105 & 0.271 \\
\hline $\begin{array}{l}\text { Global cognition, } \\
\text { mean (SD) }\end{array}$ & $14.4(5.2)$ & $15.4(4.9)$ & $13.0(5.0)$ & -2.860 & 0.005 \\
\hline $\begin{array}{l}\text { Episodic memory, } \\
\text { mean (SD) }\end{array}$ & $6.6(3.4)$ & $7.1(3.2)$ & $5.8(3.4)$ & -2.357 & 0.020 \\
\hline $\begin{array}{l}\text { Orientation to time, } \\
\text { mean (SD) }\end{array}$ & $3.1(1.2)$ & $3.4(1.0)$ & $2.8(1.3)$ & -2.894 & 0.005 \\
\hline
\end{tabular}


Table 3 Continued

\begin{tabular}{|c|c|c|c|c|c|}
\hline Characteristic $^{*}$ & Overall & No disability & Disability & $\mathbf{t} / \chi^{2}$ & $\mathrm{Pt}$ \\
\hline & $(n=152)$ & $(n=91)$ & $(n=61)$ & & \\
\hline Attention/numerical ability, mean (SD) & $3.0(1.9)$ & $3.2(1.9)$ & $2.7(2.0)$ & -1.400 & 0.164 \\
\hline
\end{tabular}

*Values are mean (SD) or $\mathrm{n}(\%)$ as appropriate.

†P value of the $\chi^{2}$ test (categorical variables) or t-test (continuous variables) of the difference between the cases and non-cases of ADL disability at the end of follow-up (2015).

ADL, activities of daily living; BMI, body mass index; CESD-10, 10-item center for epidemiologic studies depression scale; GS, grip strength; PEF, peak expiratory flow.

As a result, evaluation of ability in time and mental space processing might help to distinguish different stages of cognitive impairment and disability. Note that impaired orientation, which might be related to disruption of neural plasticity and cerebral integrity, has also been considered an independent predictor for increased cardiovascular events and mortality. ${ }^{52}$ Our study found that decreased orientation to time in the older participants with COPD increased about 1.46 times of disability incidence over 2-year follow-up, and this was affected by lung function and medical resources, suggesting that COPD individuals with declined time orientation may be more likely to present mild cognitive impairment ${ }^{4-51}$ and decompensation of cortical function because of the disrupted neuroplasticity, therefore developed into disability. In the cross-sectional study, we found a positive correlation between pulmonary function and cognitive level, suggesting that the decline of cortical plasticity presented by the decline in orientation to time could be affected by the interaction of pulmonary function deterioration and other hypoxia-related factors in older patients with COPD.

It has been found that hypoxia/hypercarbia can lead to deficits in attention, executive function, psychomotor and linguistic abilities in COPD and obstructive sleep apnoea. ${ }^{19}$ Besides, there seems to be other contribution of a mechanism beyond hypoxia/hypercarbia to certain cognitive domains in obstructive respiratory disease, such as inflammatory mediators and a sedentary lifestyle. ${ }^{1853}$ For example, limited mobility has been found to be associated with cognitive impairments. ${ }^{53}$ In the cross-sectional analysis of this study, we found that disability was an independent risk factor for poorer visuospatial function in COPD. Because visuospatial ability is closely related to psychomotor and motor function, ${ }^{54}$ disability may result in limited daily activities, thereby worsening visuospatial ability, and vice versa. Thus, clinicians and researchers should pay more attention to this domain of cognitive function in older adults with COPD, this may help to improve self-management and adherence to medical treatment to reduce the incidence of disability. In addition, cognitive impairment and functional disability were independently associated with in-hospital mortality and the need for postacute care in older patients with COPD. Compared with patients with COPD and with disabilities who had no cognitive impairment, those with cognitive dysfunction increased about 8.6 times of in-hospital mortality. ${ }^{55}$ Therefore, improving cognitive function in older adults with COPD may reduce the risk of readmission and in-hospital mortality, enhance control of symptoms and improve the quality of life.

A major strength of this study is that a cross-sectional analysis combined with a longitudinal analysis was used to confirm the association between disability and domainspecific cognitive function in a relatively large population of older individuals with COPD, with the availability of extensive information on sociodemographic, comorbidities, health-related physical and mental status. This study has some limitations. First, a causal association of disability with a declined orientation to time in COPD should still be cautious because only variables with differences between groups were adjusted in the longitudinal analysis. Second, many older individuals $(78 \%)$ with COPD were excluded from the longitudinal analysis because of missing information on related observation variables, and the follow-up period was only about 2 years. Third, some important measurements related to COPD, such as Global Initiative for Chronic Obstructive Lung disease (GOLD) stage and vital capacity, were not included in the study. Further studies are needed to examine the mechanism underlying cognitive impairment in older patients with COPD and with disability and reduce the incidence of disability in patients with COPD.

\section{CONCLUSIONS}

Our results suggest that among the domain-specific cognitive functions, orientation to time and visuospatial ability may be most vulnerable to the presence of disability in older adults with COPD. Moreover, a decline in orientation to time in older people with COPD may have increased the incidence of disability over time. Cognitive training on the two cognitive domains, or combined with other rehabilitation therapy, might help to prevent or improve disability in older people with COPD.

Acknowledgements The authors thank the China Center for Economic Research, National School of Development at Peking University for providing the CHARLS data. The data collection of the CHARLS was supported by the National Institute on Aging (grants R21-AG031372-01, R01-AG037031-01 and R01-AG037031-03S1), the 
Word Bank (contracts 7145915 and 71459234), the National Science Foundation of China (grants 70773002, 7091010722 and 71130002) and Peking University.

Contributors BG and CW conceptualised the study. BG and CW conducted data curation and analyses. BG and CW interpreted the results, performed data visualisation and wrote the manuscript. CW and SS supervised the study. All authors contributed to and approved the final manuscript.

Funding This study was supported by the National Natural Science Foundation of China (81601168), the Beijing Natural Science Foundation (7202086) and the 2019 Hongrui Young Scholar Development Research Fund of Peking University School of Nursing (HRHL19ZD01). The funding agencies have no role in design, analysis, interpretation or writing of this study.

Competing interests None declared.

Patient and public involvement Patients and/or the public were not involved in the design, or conduct, or reporting or dissemination plans of this research.

Patient consent for publication Not required.

Provenance and peer review Not commissioned; externally peer reviewed.

Data availability statement Data are available in a public, open access repository. The data used in this study are publicly and freely available from the China Health and Retirement Longitudinal Study (CHARLS) at charls.pku.edu.cn/en.

Open access This is an open access article distributed in accordance with the Creative Commons Attribution Non Commercial (CC BY-NC 4.0) license, which permits others to distribute, remix, adapt, build upon this work non-commercially, and license their derivative works on different terms, provided the original work is properly cited, appropriate credit is given, any changes made indicated, and the use is non-commercial. See: http://creativecommons.org/licenses/by-nc/4.0/.

\section{ORCID iD}

Chao Wu http://orcid.org/0000-0003-1824-9923

\section{REFERENCES}

1 Hanson C, Bowser EK, Frankenfield DC, et al. Chronic obstructive pulmonary disease: a 2019 evidence analysis center evidencebased practice guideline. J Acad Nutr Diet 2020. doi:10.1016/j. jand.2019.12.001. [Epub ahead of print: 17 Feb 2020].

2 Weiss A, Porter S, Rozenberg D, et al. Chronic obstructive pulmonary disease: a palliative medicine review of the disease, its therapies, and drug interactions. J Pain Symptom Manage 2020;60:135-50.

3 Sapey E, Bafadhel M, Bolton CE, et al. Building toolkits for COPD exacerbations: lessons from the past and present. Thorax 2019;74:898-905.

4 GBD. Chronic respiratory disease collaborators. global, regional, and national deaths, prevalence, disability-adjusted life years, and years lived with disability for chronic obstructive pulmonary disease and asthma, 1990-2015: a systematic analysis for the global burden of disease study 2015. Lancet Respir Med 2015;2017:691-706.

5 MacNee W, Rabinovich RA, Choudhury G. Ageing and the border between health and disease. Eur Respir J 2014:44:1332-52.

6 Li X, Cao X, Guo M, et al. Trends and risk factors of mortality and disability adjusted life years for chronic respiratory diseases from 1990 to 2017: systematic analysis for the global burden of disease study 2017. BMJ 2020;368:m234.

7 GBD 2016 occupational chronic respiratory risk factors collaborators. Global and regional burden of chronic respiratory disease in 2016 arising from non-infectious airborne occupational exposures: a systematic analysis for the global burden of disease study 2016. Occup Environ Med 2020;77:142-50.

8 Wang C, Xu J, Yang L, et al. Prevalence and risk factors of chronic obstructive pulmonary disease in China (the China pulmonary health [CPH] study): a national cross-sectional study. Lancet 2018;391:1706-17.

9 Negewo NA, Gibson PG, McDonald VM. Copd and its comorbidities: impact, measurement and mechanisms. Respirology 2015;20:1160-71.

10 Cavaillès A, Brinchault-Rabin G, Dixmier A, et al. Comorbidities of COPD. Eur Respir Rev 2013;22:454-75.

11 Dodd JW. Lung disease as a determinant of cognitive decline and dementia. Alzheimers Res Ther 2015;7:32.

12 Lahousse L, Vernooij MW, Darweesh SKL, et al. Chronic obstructive pulmonary disease and cerebral microbleeds. The Rotterdam study. Am J Respir Crit Care Med 2013;188:783-8.

13 Lecheler L, Richter M, Franzen DP, et al. The frequent and underrecognised co-occurrence of acute exacerbated COPD and depression warrants screening: a systematic review. Eur Respir Rev 2017;26:170026.

14 Vanfleteren LE, Beghe B, Andersson A, et al. Multimorbidity in COPD, does sleep matter? Eur J Intern Med 2020;73:7-15.

15 Yohannes AM, Chen W, Moga AM, et al. Cognitive impairment in chronic obstructive pulmonary disease and chronic heart failure: a systematic review and meta-analysis of observational studies. J Am Med Dir Assoc 2017;18:451.e1-451.e11.

16 Dodd JW, Getov SV, Jones PW. Cognitive function in COPD. Eur Respir J 2010;35:913-22.

17 Campman CAM, Sitskoorn MM. Better care for patients with COPD and cognitive impairment. Lancet Respir Med 2013;1:504-6.

18 Cleutjens FAHM, Spruit MA, Ponds RWHM, et al. Cognitive functioning in obstructive lung disease: results from the United Kingdom Biobank. J Am Med Dir Assoc 2014;15:214-9.

19 Olaithe M, Bucks RS, Hillman DR, et al. Cognitive deficits in obstructive sleep apnea: insights from a meta-review and comparison with deficits observed in COPD, insomnia, and sleep deprivation. Sleep Med Rev 2018;38:39-49.

20 Sanders CL, Rattinger GB, Deberard MS, et al. Interaction between physical activity and genes related to neurotrophin signaling in latelife cognitive performance: the Cache County study. J Gerontol A Biol Sci Med Sci 2020;75:1633-42.

21 García-Hermoso A, Ramírez-Vélez R, Celis-Morales CA, et al. Can physical activity attenuate the negative association between sitting time and cognitive function among older adults? A mediation analysis. Exp Gerontol 2018;106:173-7.

22 Locke E, Thielke S, Diehr P, et al. Effects of respiratory and nonrespiratory factors on disability among older adults with airway obstruction: the cardiovascular health study. COPD 2013;10:588-96.

23 Antonelli-Incalzi R, Corsonello A, Trojano L, et al. Correlation between cognitive impairment and dependence in hypoxemic COPD. J Clin Exp Neuropsychol 2008;30:141-50.

24 Eisner MD, Iribarren C, Blanc PD, et al. Development of disability in chronic obstructive pulmonary disease: beyond lung function. Thorax 2011;66:108-14.

25 Yohannes AM, Raue PJ, Kanellopoulos D, et al. Predictors of all-cause mortality in patients with severe COPD and major depression admitted to a rehabilitation Hospital. Chest 2016;149:467-73

26 Baird C, Lovell J, Johnson M, et al. The impact of cognitive impairment on self-management in chronic obstructive pulmonary disease: a systematic review. Respir Med 2017;129:130-9.

27 Martinez $\mathrm{CH}$, Richardson CR, Han MK, et al. Chronic obstructive pulmonary disease, cognitive impairment, and development of disability: the health and retirement study. Ann Am Thorac Soc 2014;11:1362-70.

28 Xiang $\mathrm{Y}$, Zare H, Guan C, et al. The impact of rural-urban community settings on cognitive decline: results from a nationally-representative sample of seniors in China. BMC Geriatr 2018;18:323.

29 Qin T, Yan M, Fu Z, et al. Association between anemia and cognitive decline among Chinese middle-aged and elderly: evidence from the China health and retirement longitudinal study. BMC Geriatr 2019;19:305

30 Huang W, Zhou Y. Effects of education on cognition at older ages: evidence from China's great famine. Soc Sci Med 2013;98:54-62.

31 Wang T, Wu Y, Sun Y, et al. A prospective study on the association between uric acid and cognitive function among middle-aged and older Chinese. J Alzheimers Dis 2017;58:79-86.

32 McArdle JJ, Fisher GG, Kadlec KM. Latent variable analyses of age trends of cognition in the health and retirement study, 1992-2004. Psychol Aging 2007;22:525-45.

33 Sha T, Cheng W, Yan Y. Prospective associations between pulse pressure and cognitive performance in Chinese middle-aged and older population across a 5-year study period. Alzheimers Res Ther 2018;10:29

34 Zuo M, Gan C, Liu T, et al. Physical predictors of cognitive function in individuals with hypertension: evidence from the CHARLS basline survey. West J Nurs Res 2019;41:592-614.

35 Li J, Cacchione PZ, Hodgson N, et al. Afternoon napping and cognition in Chinese older adults: findings from the China health and retirement longitudinal study baseline assessment. J Am Geriatr Soc 2017;65:373-80.

36 Lawton MP, Brody EM. Assessment of older people: selfmaintaining and instrumental activities of daily living. Gerontologist 1969;9:179-86.

37 Huang QB, Wang XH, Chen G. Reliability and validity of 10-item CES-D among middle aged and older adults in China. China $J$ Health Psychol 2015;23:1036-41.

38 Rodríguez-Rodríguez P, Jiménez-García R, Hernández-Barrera $\mathrm{V}$, et al. Prevalence of physical disability in patients with chronic 
obstructive pulmonary disease and associated risk factors. COPD 2013;10:611-7.

39 Centers for Disease Control and Prevention (CDC). Prevalence and most common causes of disability among adults--United States, 2005. MMWR Morb Mortal Wkly Rep 2009;58:421-6.

40 Palacios-Ceña D, Jiménez-García R, Hernández-Barrera $V$, et al. Has the prevalence of disability increased over the past decade (2000-2007) in elderly people? A Spanish population-based survey. $J$ Am Med Dir Assoc 2012;13:136-42.

41 Hootman JM, Helmick CG, Brady TJ. A public health approach to addressing arthritis in older adults: the most common cause of disability. Am J Public Health 2012;102:426-33.

42 Katz PP, Julian LJ, Omachi TA, et al. The impact of disability on depression among individuals with COPD. Chest 2010;137:838-45.

43 Mohamed-Hussein AAR, Makhlouf HA, Selim ZI, et al. Association between hand grip strength with weaning and intensive care outcomes in COPD patients: a pilot study. Clin Respir $J$ 2018;12:2475-9.

44 Lee J, Sung J, Choi M. The factors associated with subjective cognitive decline and cognitive function among older adults. $J$ Adv Nurs 2020;76:555-65.

$45 \mathrm{Kim}$ MJ, Tsutsumimoto K, Doi T, et al. Relationships between cognitive leisure activities and cognitive function in older adults with depressive symptoms: a cross-sectional study. BMJ Open 2020;10:e032679.

46 Jing Z, Li J, Wang Y, et al. The mediating effect of psychological distress on cognitive function and physical frailty among the elderly: evidence from rural Shandong, China. J Affect Disord 2020;268:88-94.

47 Cross NE, Carrier J, Postuma RB, et al. Association between insomnia disorder and cognitive function in middle-aged and older adults: a cross-sectional analysis of the Canadian longitudinal study on aging. Sleep 2019;42:zsz114.

48 Liu T, Luo H, Tang JY, et al. Does lifestyle matter? individual lifestyle factors and their additive effects associated with cognitive function in older men and women. Aging Ment Health 2020;24:405-12.

49 Guerrero-Berroa E, Luo X, Schmeidler J, et al. The MMSE orientation for time domain is a strong predictor of subsequent cognitive decline in the elderly. Int $J$ Geriatr Psychiatry 2009;24:1429-37.

50 Schultz-Larsen K, Lomholt RK, Kreiner S. Mini-Mental status examination: a short form of MMSE was as accurate as the original MMSE in predicting dementia. J Clin Epidemiol 2007;60:260-7.

51 O'Keeffe E, Mukhtar O, O'Keeffe ST. Orientation to time as a guide to the presence and severity of cognitive impairment in older hospital patients. J Neurol Neurosurg Psychiatry 2011;82:500-4.

52 Rostamian S, van Buchem MA, Jukema JW, et al. Lower performance in orientation to time and place associates with greater risk of cardiovascular events and mortality in the oldest old: Leiden 85-plus study. Front Aging Neurosci 2017;9:307.

53 Bernabeu-Mora R, Medina-Mirapeix F, Llamazares-Herrán E, et al. The short physical performance battery is a discriminative tool for identifying patients with COPD at risk of disability. Int J Chron Obstruct Pulmon Dis 2015:10:2619-26.

54 Manza P, Zhang S, Li C-SR, et al. Resting-State functiona connectivity of the striatum in early-stage Parkinson's disease: cognitive decline and motor symptomatology. Hum Brain Mapp 2016;37:648-62.

55 Spannella F, Giulietti F, Cocci G, et al. Acute exacerbation of chronic obstructive pulmonary disease in oldest adults: predictors of inhospital mortality and need for post-acute care. J Am Med Dir Assoc 2019;20:893-8. 